ness. A very real stigma is associated with such terms. Perhaps health professionals, who should after all be familiar with the negative impact of stigma and low self-esteem, need to take a lead in this field by banning such terms.

Frank Houghton, Health Geographer Department of Public Health, Mid-Western Health Board, Limerick, Ireland.

\section{Evolutionary theory in psychiatry and psychology}

Charles Darwin's birthday, February 12, was recently marked by 'Darwin Day' celebrations worldwide, serving to highlight the seminal contribution of his theory of evolution to modern science. However, the role of evolutionary theory in psychiatry and psychology remains contentious. RT Abed's editorial in support of evolutionary psychiatry, published in the British Journal of Psychiatry in 2000, was followed by a heated debate in the correspondence pages of that journal. ${ }^{\prime}$

Proponents argue that evolutionary psychiatry and psychology provide a cohesive and robust theoretical framework within which to study human emotions and behaviour, generating useful research questions and clinically meaningful results. They claim that evolutionary theories provide 'ultimate' explanations (why a trait or system exists) in contrast to the 'proximate' explanations (how a trait or system works) provided by the other neurosciences such as genetics and neurochemistry.

Evolutionary psychiatrists view psychiatric illnesses such as mood disorders, psychotic illnesses, anxiety disorders and phobias as accentuations or dysregulation of normal states which in themselves are adaptive responses to individual and group conflict or environmental threats. Such theories resonate with Carl Jung's ideas of the 'collective uncon- scious' and some proponents of evolutionary psychiatry such as Anthony Stevens have their backgrounds in Jungian analysis.

To use the example of phobias, evolutionary psychiatrists argue that, in the more hostile and dangerous environment of our ancestors, those who were avoidant of certain animals and insects had a reproductive advantage and passed their phobic genes on to subsequent generations. In the case of mood disorders, however, evolutionary psychiatrists put forward more complicated explanations, describing depression and mania as accentuations of normal and adaptive responses to losses and gains that affect the reproductive fitness of the individual. The depressive state, for example, may help facilitate adjustment to a loss or lead an individual to avoid (and therefore survive) a conflict they are likely to lose. ${ }^{2}$ In contrast to these 'ultimate' explanations, Abed describes the monoamine theory of depression as a 'proximate', reductionist and unsatisfactory one.

Critics of evolutionary psychology and psychiatry question its theoretical basis and clinical relevance. They argue that the untestable nature of its theories means that different and sometimes conflicting explanations for human behaviours can be accommodated in evolutionary psychology and psychiatry. Rose refers to the discipline as "little more than an untestable bunch of anecdotes based upon a priori ideological convictions'.

Ultimately, only time will tell whether evolutionary psychology and psychiatry are selected to survive from among a plethora of competing paradigms.

Henry O'Connell, Research fellow and lecturer in Old Age Psychiatry Mercer's Institute for Research on Ageing St James's Hospital, Dublin 8, Ireland.

References

1. Abed, RT. Psychiatry and Darwinism. Time to reconsider? Br J Psychiatry 2000; 177: 1-3.

2. Stevens A and Price J. Evolutionary Psychiatry: A New Beginning (2nd ed). London: Routledge, 2000.

3. Rose S and Lucas P. Evolutionary psychology revisited (letter). Br J Psychiatry 2001; 178: 573 .

\section{Textbook of clinical psychiatry}

\section{The American Psychiatric Publishing Textbook of clinical psychiatry. Fourth Ed. Hales RE, Yudofsky SC. Washington DC: American Psychiatric Publishing, 2003. 1,647 pages plus index.}

This classic textbook is a massive, encyclopedic tome that took me five months to read. It purports to adopt GL Engel's biopsychosocial model. In order to conserve space, 10 chap- ters were dropped from the preceding edition and DSM-IVTR accompanies the book as a CD-ROM.

The text is clinical rather than the usual mixture of basic science and bread-and-butter psychiatry. There are four parts to the book: theory and foundations (from genetics to neuropsychology); disorders (as per DSM-IV-TR); treatments (heavy on psychological therapies); and 'special clinical topics' (suicide, violence, women, old age, culture, law, and ethics).

The style is very American. This is reflected in the literature references, the legal discussion, a complete chapter on 